\title{
Revisiting Controlled Digital Lending Post-ReDigi
}

Michelle M. Wu

Georgetown University Law Center, mmw84@law.georgetown.edu

This paper can be downloaded free of charge from:

https://scholarship.law.georgetown.edu/facpub/2134

https://ssrn.com/abstract=3328897

Forthcoming in First Monday, Vol. 24, No. 5, May 2019.

This open-access article is brought to you by the Georgetown Law Library. Posted with permission of the author. Follow this and additional works at: https://scholarship.law.georgetown.edu/facpub

Part of the Intellectual Property Law Commons, and the Law and Society Commons 


\section{Revisiting Controlled Digital Lending Post-ReDigi \\ Michelle M. Wu}

Now that the Second Circuit has ruled on the ReDigi appeal, some libraries and users may be curious to see how the decision factors into controlled digital lending (CDL) efforts. To understand the interest and the implications, we first need to establish the basic contours of United States copyright, fair use, CDL, and ReDigi.

\section{United States Copyright}

From its beginnings in the United States Constitution, copyright has sought to balance the interests between authors and the public. ${ }^{1}$ The debates and documents surrounding every subsequent piece of copyright legislation demonstrate how difficult this balance is as well as Congress' commitment to maintaining it.

Given those interests, it should be unsurprising that the nation's copyright laws explicitly recognize both. Section 106 reserves to the copyright owner broad control over the exclusive rights of reproduction, distribution, the making of derivative works, public display, and public performance. ${ }^{2}$ To guard public interest, though, statutory exceptions exist to permit acts under certain circumstances that would otherwise qualify as infringement. Those exceptions include resale, ${ }^{3}$ interlibrary loan copies, ${ }^{4}$ and providing materials to the print disabled, among others. ${ }^{5}$ The broadest exception by far is fair use:

Notwithstanding the provisions of sections 106 and 106A, the fair use of a copyrighted work, including such use by reproduction in copies or phonorecords or by any other means specified by that section, for purposes such as criticism, comment, news reporting, teaching (including multiple copies for classroom use), scholarship, or research, is not an infringement of copyright. In determining whether the use made of a work in any particular case is a fair use the factors to be considered shall include-

(1) the purpose and character of the use, including whether such use is of a commercial nature or is for nonprofit educational purposes;

(2) the nature of the copyrighted work;

(3) the amount and substantiality of the portion used in relation to the copyrighted work as a whole; and

(4) the effect of the use upon the potential market for or value of the copyrighted work.

\footnotetext{
${ }^{1}$ U.S. CONST. Art I, Sec 8, Cl 8.

217 U.S.C. §106.

317 U.S.C. §109.

${ }^{4} 17$ U.S.C. §108.

517 U.S.C. §121.
} 
The fact that a work is unpublished shall not itself bar a finding of fair use if such finding is made upon consideration of all the above factors. ${ }^{6}$

Fair use "permits courts to avoid rigid application of the copyright statute when, on occasion, it would stifle the very creativity which that law is designed to foster." ${ }^{7}$ It is not a strict test. While the four factors named in the statute must be applied by the courts, judges are not restricted to considering only those factors. ${ }^{8}$ Outcomes, therefore, are not predictable and are only discoverable through the analysis of a given case's facts ${ }^{9}$ and a court's individualized perspective on the appropriate inputs.

\section{Controlled Digital Lending}

$\mathrm{CDL}$ is a part of a library effort to ensure that legitimately acquired materials remain useable through changes in technology, which come much more rapidly now than ever before. Presently, the initiatives focus on digitizing material and lending these e-versions in place of the original physical items, but the same general principles could apply to later technologies. While CDL implementations may vary in specifics, all share common characteristics:

Properly implemented, $C D L$ enables a library to circulate a digitized title in place of a physical one in a controlled manner. Under this approach, a library may only loan simultaneously the number of copies that it has legitimately acquired, usually through purchase or donation. For example, if a library owns three copies of a title and digitizes one copy, it may use CDL to circulate one digital copy and two print, or three digital copies, or two digital copies and one print; in all cases, it could only circulate the same number of copies that it owned before digitization. Essentially, CDL must maintain an "owned to loaned" ratio. Circulation in any format is controlled so that only one user can use any given copy at a time, for a limited time. Further, $\mathrm{CDL}$ systems generally employ appropriate technical measures to prevent users from retaining a permanent copy or distributing additional copies. ${ }^{10}$

Each point raised deserves further expansion. The first requirement is that any library engaging in CDL must have legitimately acquired the physical works to be digitized, typically through gift or purchase.

\footnotetext{
${ }^{6} 17$ U.S.C. $\$ 107$.

${ }^{7}$ Campbell v. Acuff-Rose Music, Inc., 510 U.S. 569, 577, 114 S. Ct. 1164, 127 L. Ed. 2d 500 (1994), quoting Stewart v. Abend, 495 U.S. 207, 236, 110 S. Ct. 1750, 109 L. Ed. 2d 184 (1990). 4 Nimmer on Copyright $§ 13.05$ (2018)

${ }^{8}$ Swatch Grp. Mgmt. Servs. Ltd. v. Bloomberg L.P., 756 F.3d 73 at 81 (2d Cir. 2014).

${ }^{9}$ Campbell v. Acuff-Rose Music, Inc., 510 U.S. 569 at 577-78 (1994).

${ }^{10}$ Lila Bailey, et al., Position Statement on Controlled Digital Lending at https://controlleddigitallending.org/statement (last visited January 31, 2019). For more information on Controlled Digital Lending, see David R. Hansen \& Kyle K. Courtney, A White Paper on Controlled Digital Lending of Library Books at https://controlleddigitallending.org/whitepaper or the Controlled Digital Lending Fact Sheet at https://controlleddigitallending.org/faq.
} 
This means that the copyright owner received remuneration for her work at the time the physical work was first purchased or voluntarily gave away the copy herself, and that the entity copying and lending the work is an owner of a legitimately acquired copy.

The second element is format shifting. The CDL library converts the content in the physical article acquired into a different format, in this case, a digital format, with the intention of using the new format in place of the old. In instances where a library may own more than one copy, it may choose to use the new format in place of only a percentage of the owned copies, using some in their original formats and others in their converted ones. Though the digitized works are likely to be processed for optical character recognition, for searching and screen reader functionality, ${ }^{11}$ the content of the work remains the same as the original. The library makes no edits or changes to the work itself.

Third, a CDL library conforms to an own-to-loan ratio, lending out only the number of copies legitimately acquired. The number of copies a library can circulate remains the same both pre- and postformat shifting. Under CDL, a library cannot digitize a work to increase the number of copies used for lending over the number owned, though it may make copies for purposes authorized by statute or case law (e.g., preservation ${ }^{12}$ ).

Last, all adopt digital rights management (DRM) tools to control use, so that a digital version of a book cannot be copied wholesale, redistributed by the user, or accessed by more users than permitted by the number of copies the library owns. The DRM tools used in current initiatives are the same ones used by the publishing industry for their e-books - Overdrive and Adobe Digital Editions - so the protections are the same as established standards. It is conceivable that other entities will create competing platforms in the future, but all are expected to contain similar DRM restrictions.

It is important to note that CDL is not intended for everyone. not a proposal for anyone to be able to format shift and lend. It is only intended for non-profit libraries, and this has been a core aspect of the framework. This narrow configuration makes sense in context, as libraries have a unique standing in society and in copyright law ${ }^{13}$. Most libraries are non-profit, non-commercial entities charged with serving the public interest, though corporate libraries may be an exception. This article uses public, school, and academic libraries as its models. The arguments for CDL are strongest for public libraries, funded by taxpayers, with an obligation to maximize access to information resources for their communities. Spending funds repeatedly on the same content, when only the container has changed, reduces the amount of unique content a library can purchase for its users.

\footnotetext{
${ }^{11}$ Optical character recognition (OCR) for these purposes has already been reviewed by courts indirectly. Both the HathiTrust and Google courts determined that the creation of a searchable database from book digitization was fair use, and the building of such a database necessarily requires OCR. If a library goes a step further and creates a permanent audio file from the OCR, technically, it could be seen as creating a derivative work, but if its platform only reads on-the-fly, it might not reach the permanence required to be considered a work. Further, if a library provides permanent audio files only to the print disabled, this would follow the same fair use analysis in the HathiTrust case.

1217 U.S.C. $\$ 108$.

${ }^{13}$ Id.
} 


\section{ReDigi}

ReDigi is a service that facilitates resale of digital music. When a user wishes to sell music he purchased from iTunes, he can use ReDigi's Music Manager and Cloud Locker to facilitate the sale. Music Manager verifies the legitimacy of the file to be resold, prevents the seller from retaining a copy of the work on any Music-Manager-connected-device after resale, and effectuates the transfer of the music file from the seller's computer to the Cloud Locker. The Cloud Locker serves two functions, as a repository for the work and as the location from which a seller or buyer could download the item. If the seller downloads the item, it is made unavailable for sale.

ReDigi claimed that its 1.0 technology, which is the only version the court considered, did not make a copy of the work during the process but instead moved the file, packet by packet, from one computer to another and therefore should be considered a transfer instead of a reproduction. Both the district and appeals courts disagreed and determined that ReDigi had made a reproduction not a transfer. ${ }^{14}$

ReDigi claimed that first sale and fair use protected its actions, and again both courts disagreed. As first sale protects only distribution and not reproduction, it was inapplicable in this case as soon as the court determined that a reproduction (an exclusive right of the copyright holder) had occurred. In the analysis of ReDigi's actions in the light of fair use claims, the courts determined that the actions were (1) non-transformative, (2) commercial, and (3) designed to take the place of copyright owner's sales in the marketplace. For all those reasons, fair use did not apply. To understand why the court's reasoning does not apply to CDL, we look further at their analysis as well as the specifics of both ReDigi and CDL.

Analysis

Though the ReDigi court deliberately restricted their fair use analysis to the company's reproduction activities, the discussion below will discuss both reproduction and distribution within CDL, as their purposes are so intertwined that it would be difficult to address only one and not the other.

First factor - Purpose and character of use

In examining the first fair use factor, courts often look at two key issues: whether the actions are transformative and whether the use is commercial. While transformativeness is not necessary to a successful fair use case, where it is found, other aspects such as commerciality become less important in the analysis. ${ }^{15}$

The ReDigi appeals court determined that the company's actions were not transformative; the

\footnotetext{
${ }^{14}$ Capitol Records, LLC v. ReDigi Inc., 910 F.3d 649 (2018).

${ }^{15}$ Campbell v. Acuff-Rose Music, Inc. 510 U.S. 569, 579 (1994).
} 
resultant files were exactly the same as the originals, with no additional features or functions and no greater efficiency or usefulness. ${ }^{16}$ In contrast, some of the uses supported by CDL are arguably transformative under the TVEyes and ReDigi standards, described in greater detail below, in that they do improve efficiency and usefulness. At a bare minimum, shifting to a digital format with optical character recognition provides greater access to disabled individuals. For the print disabled, the digital format can be read by screen readers or converted to Braille. As the materials otherwise available to this group are very limited, digitization and distribution resulting in the availability of many more works is meaningful and has already been recognized as a legitimate fair use by the HathiTrust court. ${ }^{17}$ For the physically disabled who find retrieving physical books from the library to be difficult or impossible, digital access removes the barrier of physical distance. Similarly, CDL libraries making the digitized works searchable, showing snippets, or building a database to incorporate into library catalog search engines should be seen as transformative, as all actions have already been recognized by courts as such. ${ }^{18}$

The TVEyes court, in discussing Sony ${ }^{19}$--- a case questioning whether Sony could be held liable for the Betamax's capabilities to video record television programs as they aired and replay them--raised a less recognized theory, determining that "a secondary use may be a fair use if it utilizes technology to achieve the transformative purpose of improving the efficiency of delivering content without unreasonably encroaching on the commercial entitlements of the rights holder." ${ }^{20}$ In Sony, the court determined that the recordings enabled by the Betamax were the products of authorized timeshifting. Essentially, the TVEyes court viewed the Sony case as holding that time-shifting was transformative, as it brought convenience to users and did not cause unreasonable commercial damage. ReDigi adopted the TVEyes court's view on secondary uses and transformativeness, though narrowed it further by adding the requirement that "... the improved delivery was to one entitled to receive the content." Using Sony as an example again, the court appeared to say that the time-shifting function of the Betamax had a transformative purpose, as it brought convenience to users and only allowed them to record programs to which they had legitimate access (e.g., cable subscription). It is implied that because the user has legitimate access, there is "...no unreasonable encroachment on the commercial entitlements of the rights holder."

CDL does improve efficiency of delivery, as e-books can be transmitted more quickly than physical items and circulation becomes unbounded by the library's hours. E-materials may be checked out, returned, renewed, or recalled 24/7, without any staff assistance. It also meets ReDigi's narrower test, as those entitled to receive library books are library users and that population is the one served by

\footnotetext{
16 Id. at 661.

${ }^{17}$ Authors Guild, Inc. v. HathiTrust, 755 F.3d 87, 101-102 (2014). It must be noted, though, that while the court found the provision of works to the print disabled to be a fair use, it explicitly rejected the argument that it was a transformative use.

${ }^{18}$ Authors Guild, Inc. v. HathiTrust, 755 F.3d 87 (2014) (database); Authors Guild v. Google, Inc., 804 F.3d 202 (2015) (snippets and searchability).

${ }^{19}$ Sony Corp. of America v. Universal Studios, Inc., 464 U.S. 417 (1984).

${ }^{20}$ Fox News Network, LLC v. TVEyes, Inc., 883 F.3d 169, 177 (2d Cir. 2018).
} 
$\mathrm{CDL}$. Therefore, if this new test is used, $\mathrm{CDL}$ overall should be determined to be transformative the commercial rights of the rights holder are not unreasonably encroached.

Despite TVEyes' assessment, a more traditional reading of transformativeness would find that CDL's uses for the majority of their user populations do not qualify. A basic e-version of a physical book involves no "new expression, meaning or message," 21 and a user reading an e-book is seeking the same content as she would have with the original format. The e-version may be more convenient, reducing time spent in transit, the risk of overdue fines, and other delays, but for the sake of discussing the more common position, this article assumes that the courts will find CDL to be non-transformative or minimally transformative.

As noted above, transformativeness is not necessary to fair use. Where it is not found, commerciality plays a much higher role. ${ }^{22}$ ReDigi is a commercial enterprise, and as its actions were nontransformative, the court determined that its for-profit character weighed against fair use in factor one. ${ }^{23}$

CDL can be differentiated from ReDigi in meaningful ways. First and foremost, CDL does not involve a for-profit, commercial enterprise. The reproduction and distribution in $\mathrm{CDL}$ is consistent with non-profit libraries' core mission of lending materials in the interests of education and social development. Second, unlike ReDigi, the library in CDL is the actual owner of a copy of the work. It has legitimately acquired the copy and the copyright owner has been paid for the number of copies being lent Third, the copies in CDL are controlled through DRM as well as the library's integrated system. Unlike ReDigi, which acknowledged that its software actually did not prevent both the seller and buyer from using the "transferred" work simultaneously, ${ }^{24}$ any library deploying CDL does ensure that only one user has access to its copy at a time.

Some have asked if the ReDigi court's rejection of digital first sale undermines CDL in the analysis of the first factor. It does not, as libraries using CDL have never claimed that first sale applies to their actions, which aim to circulate a substitute, not the original item acquired. That said, CDL does use first sale and the exhaustion doctrine, ${ }^{25}$ which is broader than 109 , to support its first factor analysis.

The exhaustion doctrine simply stands for the principle that once an owner transfers a copy of her work, she has received appropriate consideration for it and loses the rights to control most downstream activities (e.g., resale). ${ }^{26}$ While she still owns the copyrighted work, she does not own the individual copy transferred. The new owner holds the rights to that copy and may dispose of it in any way he wishes (e.g., destruction), even if the copyright owner objects. ${ }^{27}$

\footnotetext{
${ }^{21}$ Campbell v. Acuff-Rose Music, Inc. 510 U.S. 569, 579 (1994).

22 Id. at 585.

${ }^{23}$ Capitol Records, LLC v. ReDigi Inc., 910 F.3d 649, 660-662 (2018).

${ }^{24}$ Id. at 654 (2018).

${ }^{25}$ While the term itself is not invoked, the principles behind the exhaustion doctrine are described in Bobbs-Merrill v. Strauss, 210 v 339 (1908).

${ }^{26}$ This is admittedly a very simplified explanation of the exhaustion doctrine, which has its basis in a long history of opposition to restraining the alienation of goods.

27 There is an exception for works of art, which have greater moral rights protections.
} 
CDL asks only that courts consider the purpose of both first sale and exhaustion and then recognize that the purpose of format shifting is consistent with the principles of both. If libraries are permitted to circulate the original article under the exhaustion doctrine, lending an e-copy effectuates the same purpose, just in a different format. Nothing in the ReDigi decision undermines that general proposition. As the Redigi appeals court acknowledged that an owner of an item containing copyrighted content can take actions that others cannot, ${ }^{28}$ and there are other instances in which a library can circulate a copy in place of the original, ${ }^{29}$ this is not an unreasonable position to take.

Because of the differences in ownership, use, and commerciality between ReDigi and CDL, factor one should weigh in favor of fair use for CDL reproduction and distribution.

Factors two and three: Nature of the work / Amount \& Substantiality Taken

These two factors have been grouped together as both courts and scholars studying fair use trends generally agree that they rarely play significant roles in outcomes. ${ }^{30}$ They are meaningless in isolation and only are understood through the lenses of factors one and four. Most recently, courts have considered these as neutral or as side considerations. ${ }^{31}$

In ReDigi, the circuit court found that the second factor was neutral but claimed that taking the entirety of a work weighed against fair use despite citing a series of cases that indicated that fair use could be sustained even when reproducing a complete digital file. ${ }^{32} \mathrm{CDL}$ also copies the entirely of a work, but the types of works bear greater resemblance to the works in the Google and HathiTrust cases. Both courts noted that the test for factor three should be whether or not the amount taken is that which is necessary to the use. ${ }^{33} \mathrm{In} \mathrm{CDL}$, the taking of the full text is necessary, as reading a book loses its value if one does not have access to the entirety of the book.

Should a court decide to apply ReDigi's reasoning on factor three to CDL, it should be noted that there is an additional aspect to be analyzed. The library would legitimately own a copy of the work it used, and ReDigi did not. In other words, while a CDL library might take all of a work, it owns a copy of it; it has not gained new content nor is using more copies than it owns. ReDigi was never the owner of a copy of the work, and any reproduction would thereby increase the number it uses.

Given the general consensus that these factors are themselves not determinative and that courts in Google and HathiTrust found fair uses even where large library collections had been digitized, this article maintains that these factors by themselves are neutral in the context of CDL.

\footnotetext{
${ }^{28}$ Capitol Records, LLC v. ReDigi Inc., 910 F.3d 649, 659 (2018) (recognizing the ability of a user to resell a digital work by putting it on a thumb drive, which would necessarily require reproduction).

${ }^{29} 17$ U.S.C. 108(b) and (c).

${ }^{30}$ Authors Guild v. Google, Inc., 804 F.3d 202, 220-221 (2015); Neil Weinstock Netanel, Making Sense of Fair Use, 15 Lewis \& Clark L. Rev. 715 at 743-744 (2011).

${ }^{31}$ Neil Weinstock Netanel, Making Sense of Fair Use, 15 Lewis \& Clark L. Rev. 715 (2011) and Barton Beebe, An Empirical Study of U.S. Copyright Fair Use Opinions, 1978-2005, 156 U. Pa. L. Rev. 549 (2008).

${ }^{32}$ Capitol Records, LLC v. ReDigi Inc., 910 F.3d 649, 662 (2018).

${ }^{33}$ Authors Guild v. Google, Inc., 804 F.3d 202, 220 (2015).
} 
The effect on the market or potential market of a work is the single most important factor of fair use, ${ }^{34}$ but it does not include all market harms in its assessment. It considers "adverse impact only by reason of usurpation of the demand for plaintiff's work through defendant's copying of protectable expression from such work." ${ }^{35}$ Damage to a work's market through other means, such as scathing criticism or parody, is not considered market harm under factor four. ${ }^{36}$

The appeals court held that there was market harm in ReDigi, finding that the service provider had no actual control of the objects being sold and that it "made reproductions of Plaintiffs' works for the purpose of resale in competition with the Plaintiffs' market for the sale of their sound recordings."

Here, as in factor one, CDL can be easily distinguished from ReDigi.

First, the parties agreed that ReDigi had no control over the copies being sold. ${ }^{37}$ Both seller and buyer could retain access to the work even after resale. All the seller had to do was to save a copy on media not connected to Media Manager (e.g., thumb drive) or delete Media Manager after resale and redownload the music file from Apple. In contrast, a CDL library controls access through its library system and DRM and can ensure that no copy is accessed simultaneously by more than a single user.

Second, CDL is not intended to compete with any market. It is intended to get full use out of an item that a library has acquired, for all of its users and despite changing technologies. Since copyright is medium neutral ${ }^{38}$--- the work, not its container, is what copyright protects --- the digitized copy replaces the legitimately acquired copy, not an unpurchased copy in the marketplace. Generally, most media neutral language refers to the recognition of a work (e.g., an e-book contains the same work as the printed version if no new content is included), but the logical conclusion follows that if copyright is medium neutral, then the principle should apply as much to format shifting on the user side as on the author side.

While the e-copy could cause market damage --- users who check out library books in any format may indeed choose not to buy them --- it is no more than the damage permitted by copyright law through circulating library materials in the first place. The own-to-loan ratio ensures that the market harm is the same nature as circulating the original, and temporary access (e.g., 2-week loan period) to an e-book by a given user causes no greater damage than temporary access to a print book. While some opponents might argue that the harm is greater, because digital works can be transmitted more quickly than print, this argument holds true with every past and future advancement in transportation. As cars replaced horses, and FedEx augmented US mail, users could reach library

\footnotetext{
${ }^{34}$ Neil Weinstock Netanel, Making Sense of Fair Use, 15 Lewis \& Clark L. Rev. 715 at 743-744 (2011). See also Harper \& Row Publishers, Inc. v. Nation Enterprises, 471 U.S. 549, 566 (1985) (describing the fourth factor as "undoubtedly the single most important element of fair use")

${ }^{35}$ Melville B. Nimmer \& David Nimmer, Nimmer On Copyright, §13.05.

${ }^{36}$ Campbell v. Acuff-Rose Music, Inc., 510 U.S. 569, 591-592 (1994).

${ }^{37}$ Capitol Records, LLC v. ReDigi Inc., 910 F.3d 649, fn 6 (2018).

${ }^{38}$ Faulkner v. Nat'I Geographic Soc'y, 409 F.3d 26, 40 (2d Cir.2005).
} 
materials faster. That online technology creates minimal friction is not a copyright issue; it is a general issue of transportation evolution and should not be used to undercut the public interest in checking out materials legitimately acquired.

Even if opponents elect to pursue the market harm argument, it would be difficult to prove. Someone who checks out a library book may not be interested enough in the book to purchase it. Even if use increases with a digital format shift, how would one determine if the new user population would have purchased the book if the library only had the print version? User statistics may actually bolster the argument against market harm, as preliminary data suggests that the digital availability bolsters print sales ${ }^{39}$ and that the majority of online e-book use is brief, seemingly more of a shelf browse or reference check than an interest in reading the full-text itself.

In a footnote, the ReDigi court provided additional insight which could be useful in CDL discussions. The court noted that "[t]o the extent a reproduction was made solely for cloud storage of the user's music on ReDigi's server, and not to facilitate resale, the reproduction would likely be fair use just as the copying at issue in Sony was fair use." ${ }^{40}$ The comment seems to indicate that reproduction services facilitating owner use of materials they legitimately own would be fair use. In the case of CDL, format shifting is intended to facilitate regular use (lending) of materials that the library owns, so it would fall squarely within this framework.

\section{Factors Considered Together}

While it is not known what additional factors a court might apply to CDL, in looking at the four known factors, CDL is so substantially different from ReDigi that the ReDigi court's conclusions should not apply. As CDL libraries seek only to circulate materials that they have legitimately acquired, respecting the own-to-loan ratio and controlling access through DRM, there is reason to believe that the unique factors surrounding CDL are sufficient to favor a finding of fair use.

\section{Other arguments}

Outside of ReDigi, CDL opponents have largely made the following three arguments: (1) Unrestricted and widespread conduct of the same sort would create market damage disfavoring fair use, (2) deprivation of licensing revenues of a known or likely to be developed market should weigh against fair use; (3) digital works lead to greater market harm because they do not degrade and therefore should fall under stricter scrutiny.

This article will take each of these in turn. The first assertion looks at common language from factor four analyses, where courts consider not only the effect of the current action but the potential

\footnotetext{
${ }^{39}$ Abhishek Nagaraj and Imke Reimers, Digitization and the Demand for Physical Works: Evidence from the Google Books Project at https://papers.ssrn.com/sol3/papers.cfm?abstract id=3339524 (last accessed March 18, 2019). ${ }^{40}$ Capitol Records, LLC v. ReDigi Inc., 910 F.3d 649, fn 16 (2018).
} 
damage should there be unrestricted and widespread conduct of the same sort. ${ }^{41}$ Unrestricted and widespread conduct among libraries could not do any greater damage than has already been discussed above. Libraries would control works through their library systems and DRM and would circulate only materials that they legitimately acquired in a different format on an own-to-loan ratio.

In delving deeper into this objection, it seems that the fears expressed focus on illegal actions users might take, such as hacking the DRM controlling a book and redistributing the work. These arguments seem to be similar to the ones made during the Sony era, ${ }^{42}$ where the content-creation industries targeted legitimate actions (e.g., Sony selling Betamax video recorders) partly out of fear of subsequent user actions. Just as it is technically possible for users to violate copyright using home recorders in ways that differ from what the court described as time shifting, (e.g., recording and selling multiple copies), library users could theoretically break the DRM on a book and redistribute it. ${ }^{43}$ However, in both cases, the infringers would not be the suppliers of the technology (e.g. Sony) or the DRM-controlled-work (CDL). They would be users who actively violate copyright laws or the laws on circumvention ${ }^{44}$. The course of action available to publishers, authors, and other copyright owners in such an occurrence would be suing the individual user. To stop libraries from engaging in CDL over fears of possible illegal user action seems overblown, akin to seeking to stop the progress of technology (e.g. photocopiers, smart phones, scanning apps) out of fears of how any given invention might make infringement easier.

The second argument is that libraries are depriving copyright owners of current or potential licensing revenues, an issue that has been raised by courts in other infringement cases. ${ }^{45}$ However, nothing in those cases or in the copyright code guarantees maximum revenues to authors. It is true that factor four is intended to "incentivize new creative works by enabling their creators to profit from them," ${ }^{46}$ but in CDL, the author has already profited from the initial sale of the work. Since the library uses only the number of copies it owns, the remuneration seems to be calibrated appropriately to the use. Further, since licensing is a relatively new revenue model, one that was not possible with print items, ${ }^{47}$ a library's use of CDL arguably restores the intended balance in copyright, allowing it to retain use of works it has purchased despite the rapidity of technology/format change.

The remaining objection is that digital works present greater market harms, as they do not deteriorate as print works do and libraries would not need to replace them, as heavy use would not

\footnotetext{
${ }^{41}$ Campbell v. Acuff-Rose Music, Inc., 510 U.S. 569, 590 (1994).

42 While Universal's court arguments in the Sony case focused on home use, news coverage made clear that content-provider industries were worried about commercial piracy that was made easier by recording devices. Kathleen K. Wiegner, Pirates v. Piranhas, Forbes, p35 (August 15, 1983); Bill McCloskey, Movie Producers Want Anti-Copy Device on VCR Makers, Associated Press (September 23, 1986).

${ }^{43}$ Note that the risk is identical to the one taken by publishers offering e-books through the same types of platforms that $\mathrm{CDL}$ uses, and that there is a similar risk even with older technologies. For example, library users can scan print books using scanning apps and distribute them.

4417 U.S.C. $§ 1201$.

${ }^{45}$ American Geophysical Union v. Texaco, 60 F.3d 913 (1994).

${ }^{46}$ Capitol Records, LLC v. ReDigi Inc., 910 F.3d 649, 662 (2018).

${ }^{47}$ Bobbs-Merrill v. Strauss, 210 U.S. 339 (1908)
} 
cause the fraying and damage that using physical materials would. The court in ReDigi made a similar statement, though in dicta, distinguishing between ReDigi's digital sales and those of used physical books and music. ${ }^{48}$ However, the argument that digital files do not degrade is incomplete. While the data does not degrade, the containers for digital files (hard drives, CDs, storage) do, just as they do with physical containers. It is not costless to maintain digital files and protect against corruption or damage, and a library might well decide to license a work from a vendor to avoid the cost of security and upkeep. Further, as any library knows, it more often seeks to repair than replace, so the actual impact on replacement costs if there is a digital format shift is questionable.

Final thoughts

As with other technology cases, ReDigi does raise the question about the capability of copyright law and the courts ${ }^{49}$ to keep up with technology. The technology under discussion in ReDigi had already been replaced by the time of the ruling and the court makes clear that it makes no determination on the legality of the current software. ${ }^{50}$ The same could be said of most technology and copyright cases, and in many cases, the technology has already been altered to avoid the criticism courts provide by the time a case is heard.

The advantage of this type of delay is that court decisions will not stop innovation; there will always be another way to get to a given goal, and chances are that industries will have identified these even before a decision is rendered. The disadvantage is that outcomes are completely unpredictable, dependent on the court's understanding of current technology, and the threat of litigation is constant. This deters innovation by the sectors that would most benefit from them - the public and non-profits. They have the fewest funds and are the most risk adverse, and yet their funds may more effectively to used and the public interest better served by that type of innovation.

\footnotetext{
${ }^{48} \mathrm{Id}$.

${ }^{49}$ Capitol Records, LLC v. ReDigi Inc., 910 F.3d 649, fn 10 (2018).

${ }^{50}$ Id. at fn 2.
} 